\title{
THE NATIONAL INSTITUTE FOR RESEARCH IN NUCLEAR SCIENCE
}

\begin{abstract}
A $N$ article was published in Nature of April 27, p. 835, dealing with the new National Institute for Reserrch in Nuclear Science, and some of the many problems, administrative and scientific, raised by the establishment of the Institute, were mentioned. The very scope of the proposals makes it essential that the project should receive careful consideration, and comments were therefore invited from a number of leading scientists who are not already committed to the Institute by membership of the governing body. We print below their replies.
\end{abstract}

Str Edward Appleton, G.B.E., K.C.B., F.R.S., Principal and Vice-Chancellor, University of Edinburgh

IT is a reflexion of British progress in physical science that experimental equipment becomes of a more ambitious and elaborate nature. Most of the experiments requiring only modest apparatus, controllable by a single individual, have already been carried out in certain fields of inquiry ; though we may hope that there are still people who will not be too much influenced by this. In two notably live branches of science to-day, namely, nuclear physics and radio-astronomy, some of the necessary equip. ment has become so large and intricate that its duplication in university research centres generally becomes prohibitive on grounds of both space and cost. That is why the proposal to set up a National Institute for Research in Nuclear Science is to be welcomed.

I do not share the fears that have been expressed concerning the operation of the Institute as a monopolistic enterprise; for I am sure that it can be left to the governing body to see that the overall national interest, and that includes the welfare of our universities, is duly served. But I am concerned about an entirely different matter, and that is to ensure that existing university nuclear physics groups, with their more modest machines and other equipment, continue to receive adequate support. Universities recognize their function as being the two-fold one of training the young research worker as well as advancing human knowledge. There is a lot to be said for the simpler type of experiment, conducted by one or two individuals, as the student's first essay in scientific inquiry. One does not learn a great deal by being in charge of only one of the controls of a huge machine. So I plead the cause of individual, as well as team, research.

Prof. W. E. BURCham, F.R.S., University of Birmingham

ONE encouraging feature of the study of high-energy nuclear physics has been the degree of international co-operation which it has fostered. Physicists of many countries are using, or proposing to use, the facilities of great laboratories such as those at Berkeley or Geneva without apparently suffering any loss of prestige. It would therefore seem entirely reasonable for a federation of the universities of Great Britain to co-operate with the Atomic Energy Authority in planning and using the facilities of a large national laboratory. It is not realistic to suggest that such a laboratory should be sponsored by any single university, although future laboratories might be planned regionally to serve a group of universities.

If any such laboratory is to come into being at all and to compete usefully in high-energy physics within the next decade, its planning is already a matter of extreme urgency and must rest largely on the present staff of the Atomic Energy Authority. The sooner this burden is distributed fairly among potential users the better, and it is now for the universities to suggest conditions under which members of their staffs could be seconded to the National Institute for a time sufficient to make a real contribution. The difficulty is that this time is probably about two years at least, which is long enough to weaken considerably that unity of teaching and research which most university lecturers regard as essential to their profession.

One solution would be to have national laboratories within easy reach of all interested universities, but a more practicable one might be so to increase the size of a typical university staff that the regular absence of two or three members for a double sabbatical year could be tolerated. There would be some break in the continuity of the duties of an individual lecturer, but this would be a small price to pay for the experience and inspiration which he would gain. In order that these advantages could ultimately accrue to the universities, it would be necessary to ensure that seconded staff would not be offered permanent appointments.

I believe that the National Institute should have nothing to do directly with the nuclear energy programme, and that demands for reactors and low. energy accelerators should be left to arise from within. The Institute might well see that such relatively modest facilities were evenly distributed and generously endowed in universities, but it should primarily concern itself with its own special function. it might also provide a test-bed for new ideas, for the full-scale exploitation of which university facilities are usually inadequate and generally slow.

There are doubtless many minor practical difficulties to overcome in the present proposal, but none seems desperate providing that universities can be enabled to make a real and immediate contribution 'on the site'. This will entail the whole-hearted co-operation of the University Grants Committee; if this results in a general increase in the number of university teachers, the cause of advanced education will be noticeably furthered.

DR. A. B. D. CAssie, C.B.E., directior of the Wool Industries Research Association, Torridon, Heading. ley, Leeds

ECONOMY of materials and man-power may have compelled the decision to establish a National Institute for Research in Nuclear Science, but this policy is, in my opinion, also likely to prove right for the universities. The appeal and advantages of a university life are ample leisure to discern and 
follow up new lines of thought, and to do whatever is done with a degree of excellence which cannot be attained elsewhere. In short, university staffs should be aristocrats in their own subjects. The establishment of very costly and complex equipment at individual universities seems hard to reconcile with this fundamental feature of university life. Indeed, I should have thought that, once installed, such a machine would determine the pattern of research for a long time ahead, thus denying to academic staff the freedom to follow any other promising line of thought. How much better for the staff to feel that they have such a machine available for their work without being tied to it in future research projects. So the new National Institute should help to maintain academic freedom, which is still, I am sure, the appeal which brings the right type of man to the university staff.

Should the new Institute have a programme of its own or should it be run by a steering committee which merely allocates time to various groups wishing to use its equipment? It should, I think, have a programme of its own. A governing board as at present constituted would ensure that the programme would follow and fit in with the requirements of those interested in nuclear research. I am sure, too, that time would be made available to check important theoretical deductions or test new ideas put forward by members of university staffs. I think that the alternative of allocating time to different universities would prove exceedingly difficult to administer, and would have the defect for the universities that they might suffer unduly from absent teaching staff.

As regards the programme of work, I am not competent to deal with this other than to state that the board would have to be completely free from bureaucratic control if the programme of the Institute is to be really worth while, and sufficiently flexible to accommodate projects from those outside the Institute.

Prof. S. Devons, F.R.S., University of Manchester

THere can be little doubt that if physicists in Britain are to participate in the future development of high-energy physics, then the present, traditional organization of research on the basis of the inde: pendent resources of individual universities is inadequate. Some form of co-operation and some pooling of resources are essential. The particular type of co-operative enterprise must depend on the relationship which one considers this expensive research to bear to education, research and technological development in physics generally, as well as on the intrinsic factors which are involved by the need to create adequate facilities.

The title of the new institute sounds all-embracing, although the main incentive for its creation has been the specific need of research tools in the very high. energy field. This is the field of physics which is still predominantly academic and non-technological in its aims and outlook. The significance of this work for technological development is indirect-by maintenance of scientific research and education at the highest possible level. If the new institute is to be concerned primarily with this academic work, then its relationship with research and teaching in the universities is of vital importance. The extreme possibilities, an independent institution engaged in academic research competing with the universities and a co-operative enterprise of the universities, are clearly pointed out in the article in Nature. In any event, the physics departments in most universities are deeply involved, and the function, scope and organization of the new institute is of direct interest to them.

Regret is expressed in Nature that there has been little public discussion of the principles involved. One might add that these general issues have scarcely been discussed adequately by the university physics departments themselves. One can surely expect, however, that within the framework of the present proposals there is still room for such opinions, professional and public, to make themselves felt.

DR. D. W. HruL, director of the British Cotton Industry Research Association, Shirley Institute, Didsbury, Manchester

THE proposed National Institute for Research in Nuclear Science is a bold conception to meet a more than ordinary need. According to the announcement in the House of Commons on February 14, "the main object of the Institute will be to provide, for common use by Universities and others, facilities and equipment . ..". This object must raise problems both for the new Institute and for the universities.

While a good deal of research in nuclear science can be conducted in the universities with limited facilities, there are undoubtedly topies which should be subjects of research in universities and for which access to a nuclear reactor or to high-energy machines is essential. For example, the development of nuclear diffraction techniques for the investigation of crystal structure-a potentially valuable extension of $\mathrm{X}$-ray diffraction techniques-needs access to a pile. In the present state of knowledge, nuclear reactors and high-energy accelerators must be sited for reasons of space and/or prudence in open country. This implies a geographical separation from the universities and thereby poses an immediate problem for them by the separation of their twin functions of teaching and research.

An important function of university research itself is the training of the young research workers. Few teachers would want research students to be separated from their direction even for work involving special equipment. It seems likely, therefore, that problems considered suitable for research students will not include those that demand the special facilities of the new Institute. From where then will the demand come for the use of this special equip. ment? So far as the universities are concerned, it can apparently be only from members of the staff ; but they have teaching and administrative duties from which they cannot easily be excused. It seems, therefore, that they must use the Institute during their vacation periods or be given sabbatical periods for the purpose. This will not, by itself, serve to keep a steady load on the resources of the new Institute. The other source of external workers is likely to be the new nuclear energy industry, from which research workers might be seconded to investigate particular problems of value in, for example, the design of industrial nuclear reactors.

In order to balance the work of the Institute and keep the resources both in capital equipment and trained personnel fully employed, it will probably be necessary to establish a research programme within the Institute. There might then be a conflict 
between the demands of the research prograrnme and the desires of visiting research workers. Nevertheless, similar, if smaller, schemes have been in successful operation for many years in observatories equipped with large telescopes. Visiting astronomers use the equipment for a particular problem and share the observing time with others, including the permanent staff of the observatory. The research programme of the Institute under such a scheme could scarcely be expected to cover defence research and would necessarily therefore be directed towards fundamental studies. A director of a research association may be forgiven for suggesting that it could also be a powerful centre of nuclear research for industry.

The balance of the two functions of performing research and providing tools for others to do so would be the responsibility of a director acting under the governing board already appointed. Since, to provide staff for the Institute, he would probably have to denude the universities, the ultimate balance will probably be decided by the shortage of competent physicists. It seems certain that the greatest advantage will be reaped if the Institute is both employercarrying out independent research - and employedproviding facilities.

This arrangement still leaves untouched the problem of training young research workers, and there remains a third possibility, namely, that the permanent staff of the Institute will be recognized teachers in their own right to whom students will willingly migrate and whom universities will willingly recognize. It seems to $\mathrm{me}$ that, on whatever basis the Institute originates, it will change with time to become a de facto if not de jure advanced college of nuclear technology, providing not only for its own research and facilities for visiting staff, but also for postgraduate training in nuclear science.

Prow. J. M. Kay, professor of nuclear power, Imperial College of Science and Technology, London

THe decision to set up a National Institute for Research in Nuclear Science will receive general support from university departments concerned with nuclear energy. Some difficult problems may arise, however, over the relationship of this new Institute to the research activities of the U.K. Atomic Energy Authority. It is not always appreciated that, in addition to the Atomic Energy Research Establishment at Harwell, there is the large and highlyorganized Research and Development Branch of the Industrial Group with headquarters at Risley and with laboratories at Springfields, Windscale, Culcheth, Capenhurst and Dounreay. Will it really be necessary in the future to have three distinct research organizations in the field of nuclear science, all financed through the Atomic Energy Authority?

Presumably the division of research activities envisaged in this tripartite arrangement is for funda. mental research to be carried out at the new Institute, long-range research in the application of atomio energy to be pursued at Harwell, while research and development directed towards specific constructional projects would continue to be the responsibility of the Research and Development Branch at Risley. It is doubtfuil, however, whether it will be possible to maintain these clear distinctions, and inevitably there will be overlapping and duplication of effort at the boundaries. It could be argued that a simpler and better solution would be to have only two research organizations, one dealing with fundamental research which would be conducted so far as possible in an atmosphere of academic freedom, and the other dealing with applied research and development.

If the latter solution were to be adopted, the quickest way of setting it up would be to take the existing fundamental research activities of the Atomic Energy Research Establishment at Harwell as a basis for the new Institute. At the same time it would be necessary to combine the present applied research activities at Harwell with those of the Research and Development Branch at Risley. While the obvious criticism could be advanced that this would mean disrupting the present activities of Harwell, it is evident that some re-arrangement is envisaged in any event in view of the proposal to establish a second site at Winfrith Heath. A simple solution would be to transfer the applied research work from Harwell to Winfrith Heath, which would then become an outstation of the Risley Research and Development Branch. On this picture Harwell would become synonymous with the National Institute for Research in Nuclear Science and would then be able to concentrate its efforts on those funda. mental researches for which it is supremely well suited.

Prof. G. D. Rochester, The Durham Colleges in the University of Durham

SINCE so many members of the governing board of the new Institute are physicists with an active interest in high-energy nuclear physics, most nuclear physicists are confident that it will be run in the best interests of nuclear physics in Britain. The high proportion of university representatives will ensure close contacts with the universities. Effective contact will, however, only be secured by members of university physics departments, lecturers and research students alike, working at and with the Institute. Probably this will be done in two ways : by university departments seconding staff and students to work at the Institute for periods of up to two to three years, and by university 'truck' teams carrying out relatively short experiments involving exposures to the various beams of particles which will be available. The essential difference between the two types is that in one case, the university group, possibly with members of the Institute, will build its equipment and perform the experiment at the Institute; whereas in the second case, the group will build and assemble its equipment at its home base, take it to the Institute for the exposure, and then return to the home base to examine photographs or records and analyse theresults.

This sort of thing is not new to those who have worked in cosmic rays. Several universities in Britain have in fact maintained research teams on the Jungfraujoch, La Marmolada and the Pic du Midi, and have organized great balloon-flying expeditions abroad. The difference is that if the new Institute is to be run largely by university personnel the scale of the operation is likely to be larger. University physics departments which specialize in nuclear physics will need to increase in size to allow some members leave of absence, and finding additional staff might well prove difficult. The question of financing the groups may not be so difficult; probably the semi-permanent group could be financed by the Institute and the 'truck' team by the Depart. ment of Scientific and Industrial Research.

There is one other aspect to which attention should be directed, and that is the danger of over- 
centralization. If the best use is to be made of the universities, expensive nuclear equipment must be made available to them. This might mean the setting up of small institutes equipped with less-expensive accelerators and small reactors. The siting of these institutes will be important; but one would expect them to be in parts of the country remote from Harwell and yet as close as possible to universities.

Prof. J. Rotblat, Medical College of St. Bartholomew's Hospital, London

THE editorial article on the National Institute for Research in Nuclear Science directs attention to some dangers inherent in the setting up of the Institute. One danger which is not mentioned explicitly in that article is the possibility of further weakening independent scientific opinion in Britain. The everincreasing impact of science on the whole life of the community, coupled with the feeling among the public that scientists are shirking the responsibility for their work, makes it necessary that scientists should be free to speak about the implications of science, whether political or not, without qualms about embarrassing the Government.

It is regrettable that at a time like this a considerable fraction of nuclear scientists is precluded from expressing such independent opinion by virtue of their being employed in Government institutions, either as Civil servants or as members of the Atomic Energy Authority. It is also distressing to note that even among independent scientists there is a tendency to avoid controversial issues, because some of them feel that, being members of some board or council of a Government institution, they must not say anything in public which may imply a criticism of the official policy of the Government. The setting up of the National Institute for Research in Nuclear Science, which is bound to have close links with official Government bodies, may aggravate this situation by limiting the freedom of action of an even larger number of scientists. If this is to be avoided, it is essential that the constitution of the Institute should state clearly that its members are in no way bound by official ties and that they are completely free to express their views in public. From this point of view $I$ am in favour of a management the duty of which would be to allocate time and priorities rather than to formulate policies.

There is one other point to which I should like to direct attention. When the Institute is established, and in view of the huge sums which will be needed to operate it successfully, there may emerge a tendency to cut down expenditure on nuclear science in British universities. Such a policy would be disastrous. For the Institute to achieve its object it must be assured of a steady supply of people already trained in the basic principles of nuclear physics and with experience in some of its techniques. The physics departments of the universities, in which this preparation should obviously take place, must therefore be appropriately equipped and encouraged to carry out research in nuclear physics, even if only on a small scale. In this connexion it is worth while pointing out the anomalous situation in the University of London. In this alma mater, which turns out the largest number of graduates in the country, there is now scarcely any nuclear physics research work being carried out in its numerous schools, colleges and affiliated institutes. This is not the place to trace the sequence of events which has led to such a situation, but it certainly calls for a remedy ; this might perhaps take the shape of an auxiliary institute for nuclear research to be operated jointly by the schools of the University of London.

\section{Prof. J. SAYers, University of Birmingham}

$\mathrm{I}_{\mathrm{T}}$ is by no means certain that progress in fundamental research will be greater if a few hundred research workers are collected in a central institute than if the same workers are divided into independent groups at different centres. Perhaps there is an optimum size of organization from the point of view of the efficient use of scientists in fundamental investigations. If, on the other hand, the aim is the efficient use of limited research facilities and equip. ment, there can be little doubt about the advantage of a central institute as is now planned for nuclear science.

It may be worth while considering the possible advantages of a research group of limited size as represented, for example, by the larger university departments in Britain, as some of these advantages may be retained in the National Institute. The first that comes to mind arises from the fact that not only does research activity enhance the quality of teaching but also advanced-level teaching can leven research. It is not easy to provide adequate teaching opportunities for a large number of scientists in one place. The second possible advantage of the smaller independent groups is less easily defined. It arises from the fact that chance seems to play an appreciable part in discovery. The new ideas, which are the seeds of discovery, may often occur almost spontaneously. Since we cannot, in the nature of things, say in advance what will be the environment in which new ideas of the future will emerge, the best that can be done is to provide the maximum diversity of scientific environment. This will not be best achieved in a large institute, in which research planning and policy are under central direction, however wide the representation on any controlling board.

The solution may lie in the National Institute providing facilities which could be shared among university and other groups. This need not preclude the Institute employing scientists on its permanent staff, and indeed these might constitute one of the largest groups using the facilities of the Institute; but if the sharing of facilities is to be effective, the Institute staff should not dwarf the larger university departments.

Prof. H. W. B. SKInNer, F.R.S., University of Liverpool

IN the U.S.S.R., most of the research work seems to be done in a number of independent institutes, grouped around a university, which use some of their staffs for teaching purposes. In Britain and in the United States, on the other hand, the centres of pure research have always been in the universities, and this remains true in spite of organizations like the Brookhaven National Laboratories. Indeed, Brookhaven itself is managed by a group of universities of the eastern United States. It seems clear that we must not let the new Institute for Research in Nuclear Science upset our traditional pattern more than can be helped. We cannot afford to let it ruin the university nuclear physies research departments. For it could easily happen that oppor- 
tunities for attractive research work, coupled perhaps with high salaries as in the Government establishments, might lure all the best nuclear physics brains away from teaching into some large central institute, run on the lines of a Government establishment.

The real problem is how to avoid this. Though difficult, it should not be at all impossible to make suitable arrangements. The main points are these : (1) The existence of the Institute should not lead to a curtailment of funds for nuclear physics research in the universities. Indeed, these should be supplied with 'medium-sized' new machines when their present equipment becomes obsolete. There is a correct balance in this respect in the United States. (2) The Institute, in the not too long run, should be developed, not as one establishment but as several establishments on a regional basis. (3) A large proportion, probably the majority, of the scientists using the Institute should be university staff. This would clearly be facilitated by (2). Some increase in university staffs may be involved, to allow periods of work away, but this would not be serious. (4) Research students, working under the staff of their own universities, should be allowed to spend up to two of the three years normally necessary for the Ph.D. degree at one of the Institute establishments. (5) Each establishment should have a director and, except for financial control, it should be practically autonomous. It would thus become the high-energy research centre for the universities around it. Granted that the Institute is allowed to grow up in this way, I think we can make a success of it.

I found myself in disagreement with one doubt expressed in the article in Nature, namely, the control of research programmes. My experience in the highenergy field has taught me that these programmes more or less control themselves. That is to say, a programme is always fluid, open to change in the light of new ideas. It is not likely that, given reasonable common sense, there would ever be any dispute between a director and a university as to what experiments should be done at any moment. Of courge there might be an argument as to whether $A$ or $B$ should do a certain experiment, but this is a relatively trivial matter, and could be settled by arbitration.

No doubt the necessity for the Institute is unwelcome ; but it is futile to deny that, if we are going ahead with high-energy physics, it is a necessity. It is necessary because, although we are doing very good work in the MeV. field of nuclear spectroscopy and in the high-energy field up to $1 \mathrm{BeV}$., without the Institute we have no hope of going to higher energies, and therefore we cannot work with $K$-mesons, hyperons or anti-nucleons. Our institutions ought not to be so rigid that they cannot adapt themselves to the situation.

Dr. H. G. TAYLOR, director of the British Electrical and Allied Industries Research Association, Dorking Road, Leatherhead, Surrey

ULTRA-HIGH energy accelerators are such large and costly machines that it seems unlikely that Great Britain, or perhaps any other country, will construct more than one. There may also be some doubt whether the problem to be studied in this extreme energy-range would justify duplication in any event. The decision that this project should be centred on the Atomic Energy Authority is perhaps natural, but it does change to some degree the function of the
Authority which has not so far undertaken fundamental research in nuclear physics on anything but a modest scale. The title of the new Institute may therefore be misleading, particularly if it might be interpreted to imply that a large part of the nuclear research in Great Britain is to be concentrated in the Institute. So far this does not seem to be the intention.

High-energy accelerators are a special case, and whatever they achieve there will remain a very large amount of work on nuclear research at lower energylevels which can be done in universities with apparatus of reasonable cost or by cosmic rays. Nor should the important theoretical work done at the universities be displaced by the location of specialized experimental apparatus. Such accelerators are, in construction and operation, very much engineering projects, though of course in their design and construction they require highly qualified and specialized physicists and engineers. There must therefore be some separation between accelerator technique and the basic problems in nuclear physics which it is proposed to study. The former is so specialized that no great loss should be suffered by academic departments. It is in the planning of experiments to be carried out and the availability of the results that grounds for concern may arise. Though the present arrangements certainly appear satisfactory, it would be easy to reverse the policy at any time following, say, a change of attitude on the part of the Atomic Energy Authority. Even at best, however, the planning of experiments by an expert body could discourage the 'hair-brained' type of experiment which often pays off. The main threats undoubtedly stem from security on one hand and bureaucratic financial control on the other. These are, of course, not new.

The problems raised in general by the pursuit of fundamental research outside universities in relation to its impact on university teaching, etc., must now be accepted, and there is no real reason why the universities should lose on this account. Any research department or organization is liable to stagnate if there is not an adequate flow of personnel through it. The universities can always be expected to offer the attraction of greater freedom than either industry or Government departments, provided adequate remuneration is maintained. So long as by this means sufficient movement of staff is ensured, all should benefit. Indeed, in some cases it can prove a decided advance. Thus while the universities have long held the lead in research in physics, chemistry and the like, in engineering it is true to say that the atandards of academic teaching and research have advanced markedly since the inception of research in industrial organizations. A good example of the two-way flow engendered in this way is provided by semi-conductors, where the investigetions carried out in the laboratories of electrices concerns have passed back fundamental problems and the techniques necessary for their pursuit to academic circles.

DR. J. THomson, Director of Research, British Scientific Instrument Research Association

There are two excellent reasons for establishing a National Institute for Research in Nuclear Science. The first is that only in such an Institute can there be the essential integration of the academic sciences ensuring that real problems receive adequate atten- 
tion by balanced teams of physicists, chemists and engineers. It is no criticism of the universities to state that their traditional organization makes it difficult for them to assimilate a new technology which demands such integration. College teachers and research workers are necessarily specialists, who are forced to look only at their particular aspect of a problem; scientists in a non-academic research organization are forced to combine their efforts, so that all aspects of a problem may be considered simultaneously. This, rather than any'consideration of bricks and mortar or nuts and bolts, is the most important reason for bringing the National Institute into being. The second is that the establishment of an Institute is in accord with the modern British concept of combining for research, so that individual firms may be able to compete in development and production. In this sense the National Institute may become the research association of the new nuclear industry; one might presume that it will have established itself as an independent, useful entity when the industry is prepared to take it over and to finance it.
There need be no conflict of interests between the Institute and the universities provided that each concerns itself with its own problems. The Institute is to improve our understanding of nuclear science in its entirety and of its applications. The universities are to teach and to undertake research in nuclear physics, nuclear chemistry and nuclear engineering. In short, the universities should continue to provide the 'specialists' who (after a period of apprenticeship) may become the 'nuclear scientists' of the Institute. If the latter is to serve the nation, the governing board will do well to concentrate on taking whatever steps it deems necessary to advance the new science, secure in the knowledge that the universities will do their best to assist. The future of Britain is so dependent upon advances in industrial technology that the protocol is a minor matter. All will accept without complaint anything which furthers the magnificent work already done by the Atomic Energy Research Establishment, and scientists everywhere will wish the Board of the new National Institute well and advise it to let nothing stand in its way.

\title{
DOUNREAY EXPERIMENTAL REACTOR STATION
}

\author{
By DR. C. R. TOTTLE \\ Head of Laboratories, United Kingdom Atomic Energy Authority Industrial Group, \\ Research and Development Branch, Dounreay, Caithness
}

$\mathrm{T}$ HE completion of the Windscale plutonium. producing piles in 1950 allowed a small effort to diverted from the main commitments of the Atomic Energy Authority's Industrial Group into the field of possible power-producing reactors. During the design and construction of the Windscale establishment, the feasibility of combined plutoniumpower producers had been considered, and thoughts were naturally turned again in this direction. Nevertheless, the principle of 'breeding', in which more than one new fissile atom would result from each fission, offered great attractions, and it was decided to explore this field. It was obvious from the start that many new problems would result. The reactor would require a minimum of neutron-absorbent materials, hence it should rely on 'fast fission' and there would be no moderator. The core must be kept small to maintain neutron economy, so that its heat rating would be exceptionally high. To remove this heat, the only feasible coolants appeared to be liquid metals, and, of these, sodium offered advantages. The fast-reactor project began to grow in complexity, and as problems were solved one by one, it became obvious that an experimental reactor was the essential first step towards a power station employing fast fission and breeding. 'The safety of the reactor involved two main issues-the possibility of fires caused by the release of liquid metal coolant, and the release of fission products. A problem of containment of both hazards was thus introduced.

During the next five years, the need for an extensive programme of irradiation testing of reactor materials and components became more and more pressing. As the programme of the Industrial Group widened in scope, many problems awaited a solution or final confirmation from tests 'in pile'. This difficulty was even more evident in the Atomic Energy Research Establishment, and with the decision to build DIDO and PLUTO at Harwell, a third reactor, similar to PLUTO, was added to the facilities of the Industrial Group. This reactor was to be directed towards the more applied problems of the Group, which by this time was heavily committed on a power reactor programme. Although much of the irradiation testing for Calder Hall was carried out at Windscale, and some for the fast reactor also, it was obvious that the performance of Calder $A$ showed every prospect of a considerable improvement, and irradiation testing facilities for civil power stations must be speeded up. As the Dounreay site had already been chosen for the fast reactor, the facilities and services to be made available were extended to cope with this materials-testing reactor.

From time to time, the detailed operation of the Industrial Group plants producing and handling fissile material required revision, to avoid incidents due to the assembly of masses of fissile material (in many complex forms) closely approaching the critical size, where neutron multiplication becomes extremely rapid. Theoretical treatment from data available proved difficult, and large factors of safety were introduced. It became obvious that nore economic usage of plant and materials might be possible if experimental work covering specific materials in particular states of dispersion and environment could be carried out. Such experiments may take the form of actual assembly of fissile material packages, gradually approaching the critical mass, or employ 'exponential' methods susceptible to further theoretical treatment. The study of critical masses 